\title{
HIGH RESOLUTION AIRBORNE GEOPHYSICS AT HAZARDOUS WASTE DISPOSAL SITES*
}

\author{
L.P. Beard, J.E. Nyquist, and W.E. Doll \\ Environmental Sciences Division, Oak Ridge National Laboratory, \\ P.O. Box 2008, Oak Ridge, TN 37831-6317 \\ M. Chong Fon, and T. Jeffrey Gamey \\ Aerodat, Inc., 3883 Nashua Drive, Mississauga, Ontario, Canada L4V IR3
}

\begin{abstract}
In 1994, a high resolution helicopter geophysical survey was conducted over portions of the Oak Ridge Reservation, Tennessee. The 1800 line kilometer survey included multi-frequency electromagnetic and magnetic sensors. The areas covered by the high resolution portion of the survey were selected on the basis of their importance to the environmental restoration effort and on data obtained from the reconnaissance phase of the airborne survey in which electromagnetic, magnetic, and radiometric data were collected over the entire Oak Ridge Reservation in 1992-93.

The high resolution phase had lower sensor heights, more and higher EM frequencies, and tighter line spacings than did the reconnaissance survey. When flying over exceptionally clear areas, the high resolution bird came within a few meters of the ground surface. Unfortunately, even sparse trees and power or phone lines could prevent the bird from being towed safely at low altitudes, and over such areas it was more usual for it to be flown at about the same altitude as the bird in the reconnaissance survey, about $30 \mathrm{~m}$. Even so, the magnetometers used in the high resolution phase were $20 \mathrm{~m}$ closer to the ground than in the reconnaissance phase because they were mounted on the tail of the bird rather than on the tow cable above the bird. The EM frequencies used in the high resolution survey ranged from $7400 \mathrm{~Hz}$ to $67000 \mathrm{~Hz}$. Only the horizontal coplanar loop configuration was used in the high resolution flyovers Flight line spacings in the high resolution flyover ranged from $46 \mathrm{~m}$ over large treecovered areas to about $10 \mathrm{~m}$ in cleared waste burial grounds.

A comparison with ground conductivity and magnetic data from the WAG 11 area shows that the ground survey provides much more detail than the high resolution aerial data, however the aerial survey of WAG 11 detected the major anomalous areas-buried processing equipment, buried drums, and an area of scattered debris. Better resolution could have been obtained had the area been clear enough for the sensor to drop below treetop level. Geologic structures and contacts appear to be as accurately mapped using a coil frequency of $7400 \mathrm{~Hz}$. Apparent resistivity maps at the highest frequency $-66000 \mathrm{~Hz}$--do not correspond well with bedrock geology, but may be correlated with soil variations and the presence of buried metal.
\end{abstract}

\section{INTRODUCTION}

In this paper, we describe an application of high resolution airborne geophysical meihods at a hazardous waste site. During March and April of 1994, high resolution magnetic and electromagnetic surveys were flown over selected portions the U.S. Department of Energy's Oak Ridge Reservation (ORR) and an adjoining area. In this paper, the term 'high resolution' simply implies higher resolution when compared to the previous reconnaissance flyover. The survey covered approximately 1800 line kilometers. The goals of the survey were to test new helicopter-borne geophysical technologies in the field, to assess the resolution of this type of survey under field conditions, and to aid in planning ground geophysical investigations and other tasks related to environmental restoration. Factors which helped decide which sites would be flown were: the site's potential as a source of contamination, upcoming investigations or remediation efforts, whether high resolution data could successfully be collected at the site based upon a previous reconnaissance flyover (Doll et al., 1993, Nyquist and Doll, 1993), and the presence of flight hazards which might preclude low level flying. The sites chosen from these criteria included about 15 percent of the Oak Ridge Reservation.

The high resolution survey could be categorized as having two levels of resolution--a treetop level survey encompassing large areas ranging from 5 to $15 \mathrm{sq} \mathrm{km}$, with line spacings of 23 or $46 \mathrm{~m}$, and surveys over

* The submitted manuscript has been authored by a contractor of the U.S. Government under contract No. DEAC05-84OR21400. Accordingly, the U.S. Government retains a nonexclusive, royalty-free license to publish or reproduce the published form of this contribution, or allow others to do so, for U.S. Government purposes. 


\section{DISCLAIMER}

This report was prepared as an account of work sponsored by an agency of the United States Government. Neither the United States Government nor any agency thereof, nor any of their employees, make any warranty, express or implied, or assumes any legal liability or responsibility for the accuracy, completeness, or usefulness of any information, apparatus, product, or process disclosed, or represents that its use would not infringe privately owned rights. Reference herein to any specific commercial product, process, or service by trade name, trademark, manufacturer, or otherwise does not necessarily constitute or imply its endorsement, recommendation, or favoring by the United States Government or any agency thereof. The views and opinions of authors expressed herein do not necessarily state or reflect those of the United States Government or any agency thereof. 


\section{DISCLAIMER}

Portions of this document may be illegible in electronic image products. Images are produced from the best available original document. 
individual cleared waste area groupings (WAGs), each with an area of less than $0.5 \mathrm{sq} \mathrm{km}$. Over the WAGs, the line spacing was tighter, usually $10 \mathrm{~m}$, and where possible the sensor height was lower than in the surveys of the larger areas.

\section{SURVEY DESIGN AND SPECIFICATIONS}

The improved resolution in comparison to the reconnaissance survey resulted from a lower sensor ('bird') height, closer flight line spacings, and more and higher frequencies in the horizontal coplanar loop-loop electromagnetic system. For safety reasons, the bird had to be flown above treetop level even in areas of sparse tree cover, and thus was not always appreciably lower than in the reconnaissance survey. Sensor clearance averaged about $30 \mathrm{~m}$ in most areas. However, in a few exceptionally clear areas, the sensor clearance was less than $10 \mathrm{~m}$ above ground level. Even where the bird had a clearance equal to that of the reconnaissance survey, the magnetometers were still $20 \mathrm{~m}$ closer to the ground. In the reconnaissance survey the magnetometers were mounted $3 \mathrm{~m}$ apart and $20 \mathrm{~m}$ above the bird, whereas in the high resolution survey the magnetometers were tail mounted on the bird and were only $1 \mathrm{~m}$ apart. Although the magnetometers used in the high resolution survey were smaller, and thus less sensitive, than those in the reconnaissance survey, the signal-to-noise ratio was about the same because of the lower sensor height.

Due to the irregular topography of eastern Tennessee's Valley and Ridge province, it was difficult to achieve a very tight line spacing while flying perpendicular to the geologic and topographic strike direction. Furthermore, the areas selected for the high resolution survey tended to be longer in the direction of geologic strike, making it safer and more convenient to fly in the geologic and topographical strike direction. In some of the waste burial areas, the flight lines ran both directions. Over the larger areas, the line spacing could be up to $46 \mathrm{~m}$; however, over some of the waste areas, the spacing was as small as $10 \mathrm{~m}$.

The towed bird used in the high resolution survey had to be more maneuverable than the bird used in the reconnaissance survey. To achieve the lighter weight necessary for maneuverability, a single pair of broad band coils were used which could be tuned to five different frequencies. The frequencies chosen were $7,22,37,52$, and $67 \mathrm{kHz}$. Only the horizontal coplanar loop configuration could be used because of constraints on the bird's weight and size.

\section{CASE STUDY--WASTE AREA GROUPING 11}

Although data were collected over five sizable areas amounting to about 15 percent of the ORR, or about 20 $\mathrm{sq} \mathrm{km}$, in this paper we will discuss only those data collected over the 12 hectare area officially known as Waste Area Grouping 11, also called WAG 11 or White Wing Scrapyard. The area around WAG 11, located at the southeastern end of a large syncline in eastern Tennessee's Valley and Ridge province, is geologically complex. A major thrust fault underlies the site, dipping to the southeast at about 45 degrees. However, the fault's precise location is still a matter of debate because the regolith thickness reaches $25 \mathrm{~m}$ in the area. The lithology of the area is a complex assemblage of shale, sandstone, siltstone, dolostone, and limestone (Hatcher et al., 1992). For simplicity, directions in the following discussion and figures will use the ORR Administrative Grid. This system is rotated such that grid north is 34 degrees west of true north, so that ridges and valleys line up approximately grid east and grid west, and uses feet instead of meters as its distance scale.

In the 1950s and 1960s, WAG 11 was used primarily as an above ground storage and disposal area for contaminated debris. Materials disposed of at WAG 11 included steel tanks, vehicles, transformers, contaminated metallic debris, graphite, and assorted non-metallic materials. From 1966 to 1970, cleanup activities removed surface materials. However, there were reports that some metallic materials may have been buried at the site, and that some of the debris could extend beyond the WAG boundaries, so in 1994 a ground magnetometry and EM survey was authorized. Before the ground survey began, the high resolution aerial survey was scheduled, so WAG 11 was targeted as one of the areas to be surveyed. An annotated aerial photo of the WAG is shown in Figure 1. Waste disposed of on the WAG came from three different plants on the ORR, and each plant was responsibile for a particular area of the WAG. These areas are designated in Figure 1 by the plant names--X-10, $Y-12$, and K-25. An access road running approximately grid east-west divides WAG 11. Along the periphery of the WAG are a few monitoring wells, and a chain link fence.

The WAG 11 survey was part of a larger survey of a heavily forested $15 \mathrm{sq} \mathrm{km}$ area. Line spacings over this larger area averaged $46 \mathrm{~m}$. Average sensor height was about $30 \mathrm{~m}$. Flight lines were oriented along strike--grid west to grid east. In the WAG 11 area, line spacing was reduced to $23 \mathrm{~m}$, but sensor height remained at treetop level--20 to 30m--due to a sparse covering of trees in the WAG 11 area.

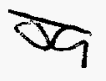


Shown in Figure 2 are apparent resistivity maps computed from $7400 \mathrm{~Hz}$ and $67000 \mathrm{~Hz}$ electromagnetic data over the area encompassing WAG 11. Superimposed on these maps are the major geologic contacts as mapped by Hatcher and others (1992). Many of the major geologic features are evident in the $7400 \mathrm{~Hz}$ apparent resistivity map. The core of a shaley syncline is apparent as a conductive zone on the east (right) side of the map. The dolomitic Knox Group appears on the west end as a very resistive unit, bounded by faults on the grid west, sout , and north sides. At both frequencies, a major thrust fault is mapped along the contact between the conductive Rome Formation on the south side--the hanging wall--and more resistive limestone units on the north side of the fault. The contact arcs through WAG 11 at about $35000 \mathrm{~N}$. A large sinkhole appears as a conductor at $42000 \mathrm{~N}$, $23000 \mathrm{E}$. Two major highways, a highway intersection, and several power lines add some cultural clutter to the apparent resistivity maps, but these had less affect on the $67000 \mathrm{~Hz}$ data than on the $7400 \mathrm{~Hz}$ data. The $67000 \mathrm{~Hz}$ apparent resistivity map, shown in Figure $2 b$, does not correlate to bedrock geology to the degree the $7400 \mathrm{~Hz}$ apparent resistivity map does. The synclinal feature is obscured. However, a localized conductive area roughly coincident with WAG 11 , and roughly the same size, accentuates it better than the $7400 \mathrm{~Hz}$ data.

Much of the waste buried on the Oak Ridge Reservation is encased in drums, larger steel containers, or in steel reinforced concrete containers, and thus provides excellent targets for the airborne magnetometers. The high resolution total field magnetic data for WAG 11, shown in Figure 3a, indicate a magnetic anomaly of about 15 $\mathrm{nT}$ on the grid east (right) side of WAG 11, a smaller anomaly in the center of the WAG, and a diffuse zone of low amplitude anomalies in the northwestern portion of the WAG. A noticeable regional gradient causes the total field to increase slightly from grid west to grid east. Figure $3 b$ shows the total magnetic field data from a walkover performed several months after the high resolution airborne survey. The grid spacings of the walkover were 10,20 , and $25 \mathrm{~m}$. The walkover magnetic data confirm the high resolution features; large magnetic anomalies are on the grid east side of WAG 11, and many smaller anomalies appear on the opposite end. At this time, the source of these anomalies is unknown, but it appears from magnetic modeling results that the objects producing the largest anomalies must amount to the magnetic equivalent of several tons of steel. The anomaly in the center corresponds to a group of buried drums, and the smaller anomalies on the northwest side of WAG 11 must be from the equivalent of several tens to hundreds of kilograms of steel scattered among several hectares of the WAG.

\section{RESOLUTION AND SENSITIVITY--MODEL STUDIES}

One major difference between airborne geophysics applied to environmental problems and airborne geophysics applied to mineral exploration is that in environmental applications, small 'discoveries' may be more important than large discoveries. Finding a few lost, potentially leaky canisters containing highly toxic materials may be more important than finding a large but relatively clean burial ground. In order to obtain the necessary resolution, the sensor must be flown as close to the ground as is safely possible. Unfortunately, even a few scattered trees can force the sensor height above treetop level, and this can reduce considerably the resolution of the airborne system. To illustrate, consider five separate clusters of steel drums, each cluster consisting of 20 drums buried $1 \mathrm{~m}$ below the earth's surface. We modeled each cluster of drums as a single dipole oriented in the same direction as the earth's field, taken as vertical in this case. We chose a reasonable pole strength for this amount of steel based on graphs from Breiner (1973). One dipole is at the origin and the other four dipoles are located $10 \mathrm{~m}$ to either side of the anomaly: north, south, east, and west. Nine flight lines were evenly spaced, $5 \mathrm{~m}$ apart, going east-west, with the central line passing over the origin. Magnetic anomalies for flight heights of $5 \mathrm{~m}$ and $20 \mathrm{~m}$ are shown in Figures $4 \mathrm{a}$ and b, respectively. At a sensor height of $5 \mathrm{~m}$, each of the five clusters produces a distinct anomaly. Peak anomalies over the drums was $93 \mathrm{nT}$. At a height of $20 \mathrm{~m}$ the five clusters cannot be distinguished from a single, larger cluster, and the peak anomaly is $7 \mathrm{nT}$. At a height of $30 \mathrm{~m}$ (not shown), the peak anomaly has been reduced to under $3 \mathrm{nT}$, barely above the noise threshold of many airborne magnetometry systems. From these calculations, it is clear that the term 'high resolution' has much different connotations in airbome magnetometry than in ground magnetometry. Airborne magnetometry may be successfully used to map the approximate boundaries of waste areas containing buried (magnetic) metallic debris, or it may be used to survey large areas of sizable features. It may serve as a guide for ground follow up, but it cannot serve as a substitute if the goal of the survey is to locate metallic objects as small as a few drums.

As was the case with the magnetometer, the height above ground of the electromagnetic transmitter and receiver coils is important in resolving adjacent conductive structures. Shown in Figure 5a is a cross-sectional view of the 3-D test model: two $5 \mathrm{ohm}-\mathrm{m}$ conductors buried $1 \mathrm{~m}$ deep in a $50 \mathrm{ohm}-\mathrm{m}$ surface layer $10 \mathrm{~m}$ thick, overlying a $300 \mathrm{ohm}-\mathrm{m}$ half-space. The conductive bodies are $40 \mathrm{~m}$ long perpendicular to the flight direction, $8 \mathrm{~m}$ wide, $6 \mathrm{~m}$ in depth extent, and their adjacent edges are separated by $8 \mathrm{~m}$. The coils are $6 \mathrm{~m}$ apart and are in the horizontal coplanar configuration. The quadrature portion of the total magnetic field, expressed in parts per 
million (ppm) of the free-space magnetic field, is shown in Figures $5 \mathrm{~b}$ and $\mathrm{c}$ for sensor heights of $5 \mathrm{~m}$ and $20 \mathrm{~m}$ respectively. Though the maximum anomaly occurs at the midpoint of the two bodies, the shoulders on either side of the peak anomaly are indicative of separate conductive bodies. At a sensor height of $5 \mathrm{~m}$, the shoulders are evident at all frequencies from $67 \mathrm{kHz}$ to $7 \mathrm{kHz}$. The largest anomalies are associated with the highest frequencies. At a sensor height of $20 \mathrm{~m}$, the total fields at all frequencies have been reduced by roughly an order of magnitude. The magnitude of the anomalies have been reduced to the extent that the shoulders, indicative of two separate bodies, would likely be obscured by a small amount of system noise or geologic variation.

\section{DISCUSSION AND CONCLUSIONS}

In our experience at Oak Ridge, we have found the multifrequency electromagnetic data to be a useful complement to the magnetometry data. However, in this specific instance, the magnetometry data have proved more useful in evaluating details within a waste area. This is because much of the material in the ORR WAGs is stored in steel containers. The sensitivity of the airborne magnetometer makes it useful for detecting even a few buried drums, provided the area is clear enough that the sensor can be flown a few meters above the ground. Unfortunately, a few widely spaced trees, power lines, or poles can be enough of a safety hazard that the sensor must be carried above tree top level. In the southeastem U.S., this often means a sensor height of $30 \mathrm{~m}$ or more must be attained. At such heights, collections of a few tens of steel drums may be separated tens of meters apart yet not be distinguishable from a single larger group of drums, either by magnetic or electromagnetic methods. An isolated group of several drums may not be detected at all.

The $7 \mathrm{kHz}$ electromagnetic data were useful in characterizing the general geology of the area, and the higher frequencies yield information on near-surface changes in soil type, moisture content, and buried metals. Some of the larger known sinkholes appear as discrete conductors at all frequencies. Other conductive area not having magnetic anomalies associated with them have been related to marshy areas, or to karst indicators such as disappearing streams.

High resolution airborne geophysics cannot substitute for dense ground geophysical coverage if the objective of the survey is to find every buried drum in an area. High resolution airborne geophysics may more appropriately be used as a tool for screening large areas, as a guide for planning ground follow up, as a means for mapping waste area boundaries, or as a method for locating some of the larger accumulations of metallic waste at a site.

\section{REFERENCES}

Breiner, S., 1973, Applications manual for portable magnetometers: Geometrics.

Doll, W.E., Nyquist, J.E., Holladay, J.S., Labson, V.F., and Pellerin, L., 1993, Preliminary results of a helicopter electromagnetic and magnetic survey of the Oak Ridge Reservation, Tennessee for environmental and geologic site characterization: SAGEEP Proceedings 1993, 281-295.

Hatcher, R.D., Jr., Lemiszki, PJ., Dreier, R.B., Ketelle, R.H., Lee, R.R., Lietzke, D.A., McMaster, W.M., Foreman, J.L., and Lee, S.Y., 1992, Status report on the geology of the Oak Ridge Reservation: ORNL/TM-12074.

Nyquist, J.E. and Doll, W.E., 1993, Comparison of surface and aerial geophysics for characterizing a hazardous waste site: a case study: Expanded abstracts of 63rd Annual Meeting and Exposition, SEG, 468-471.

\section{ACKNOWLEDGMENTS}

This research was supported in part by an appointment to the ORNL Postdoctoral Research Associates Program administered jointly by Oak Ridge National Laboratory, and by the Oak Ridge Institute for Science and Education, and by the U.S. Department of Energy under contract DE-AC05-84OR21400 with Martin Marietta Energy Systems, Inc. 


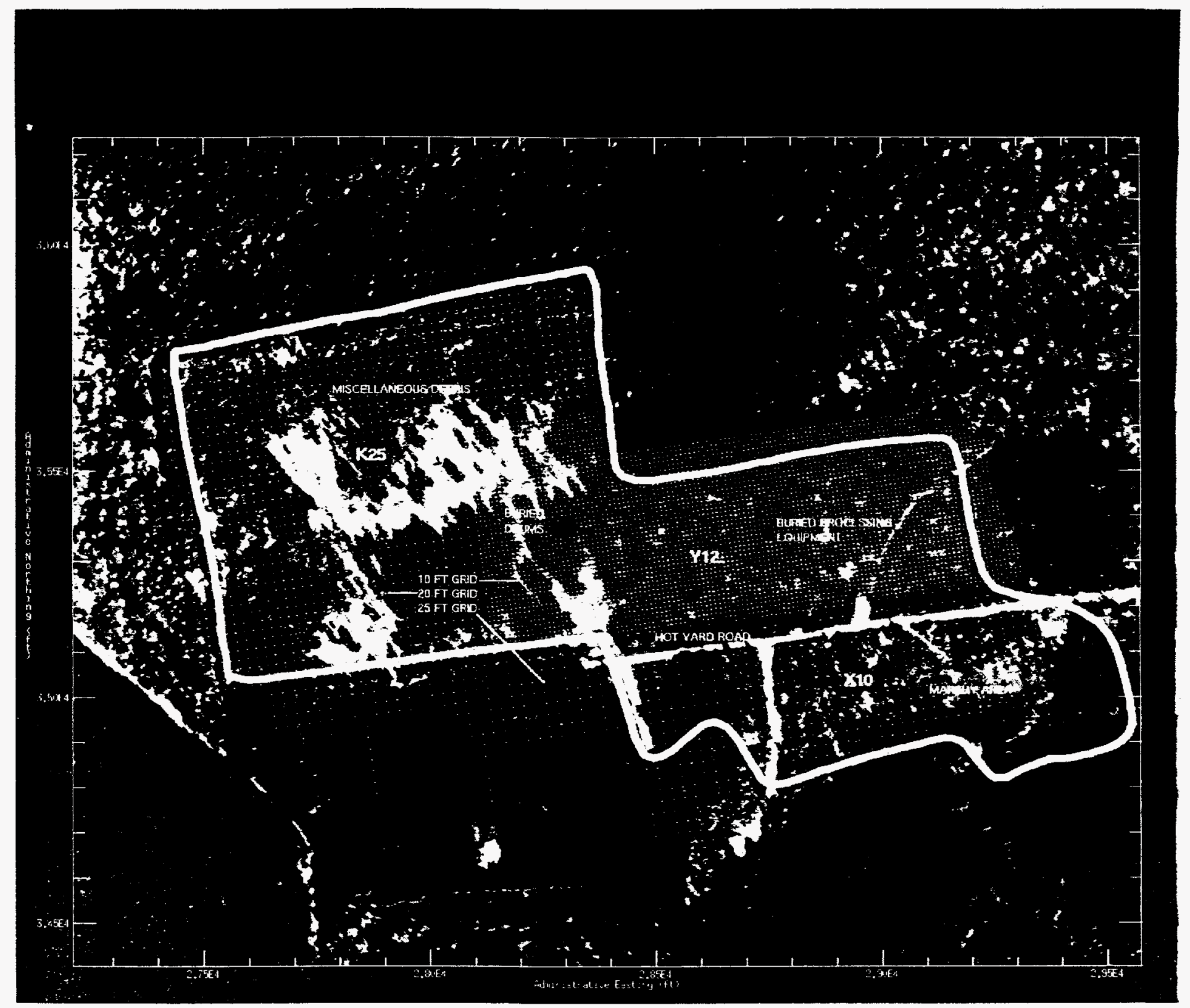

Figure 1. Aerial photograph of WAG 11 showing the WAG boundary, key features, and grid points for the ground magnetic survey. The area covered in the photograph is approximately 40 hectares ( 100 acres). 
(a)

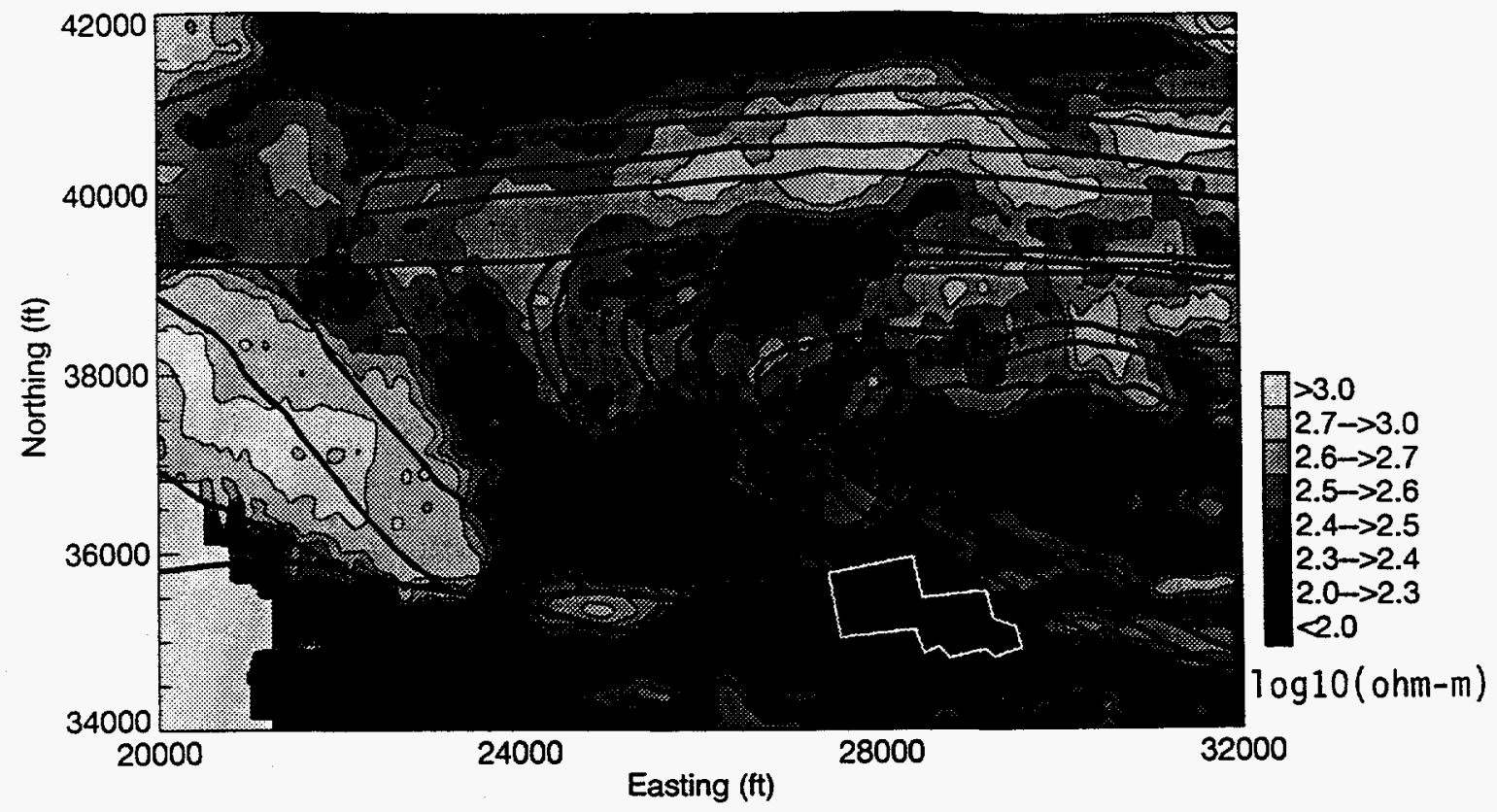

(b)

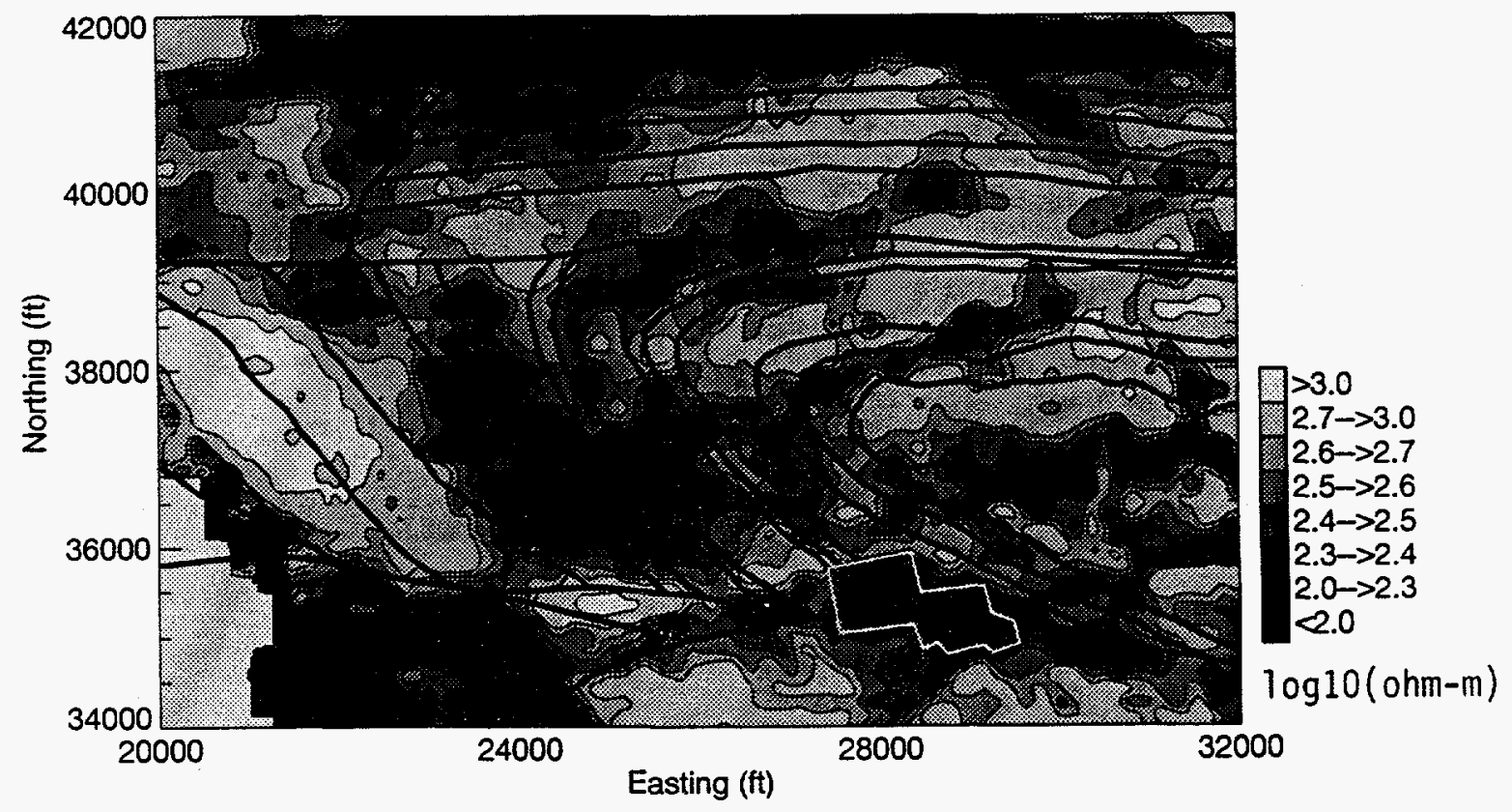

Figure 2. Apparent resistivity maps of the area around WAG 11 with geologic contacts from Hatcher and others (1992) superimposed. The boundary of WAG 11 is outlined in the lower right. (a) Apparent resistivity computed from $7400 \mathrm{~Hz}$ electromagnetic data. (b) Apparent resistivity computed from $67000 \mathrm{~Hz}$ electromagnetic data. 
(a)

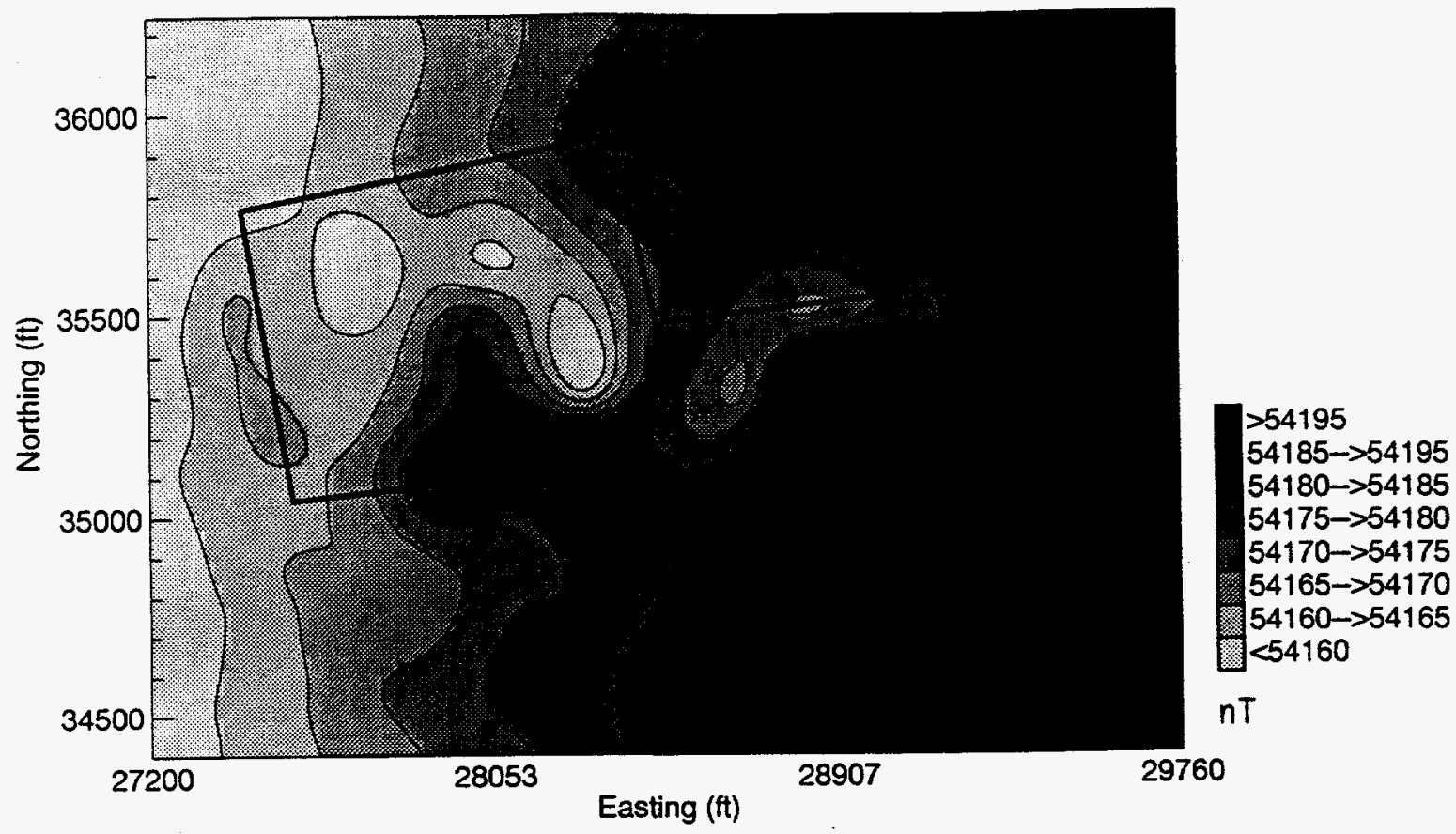

(b)

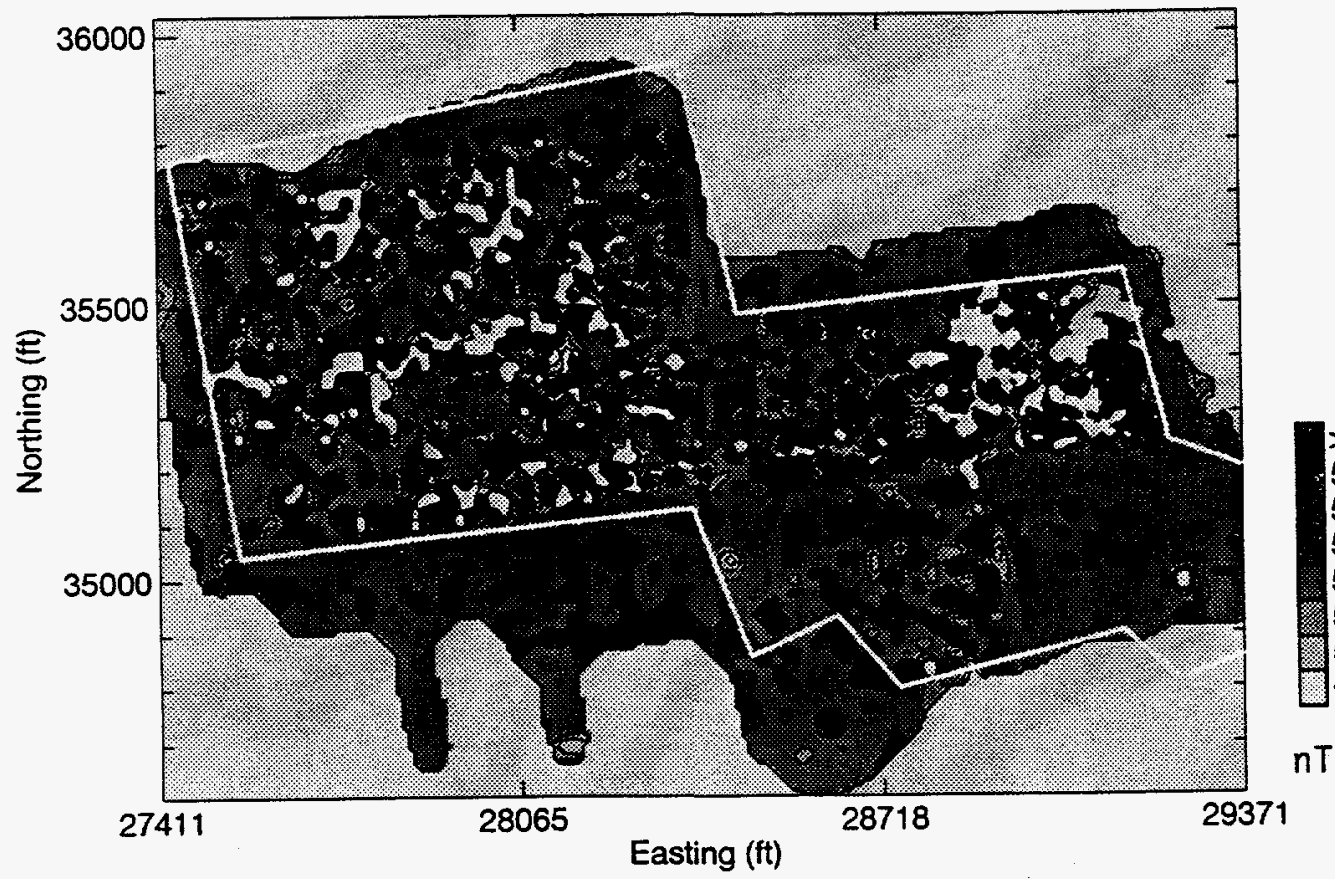

$>54900$

$54600 \rightarrow 54900$

$54300 \rightarrow>54600$

$54000 \rightarrow 554300$

$53700 \rightarrow>54000$

$53400 \rightarrow 53700$

$53100 \rightarrow 53400$

$<53100$

nT

Figure 3. Total magnetic field maps of the area around WAG 11. WAG boundary is shown. (a) High resolution aerial total magnetic field. Magnetometer was $20 \mathrm{~m}$ above ground level. (b) Ground survey total magnetic field. Magnetometer was $1.5 \mathrm{~m}$ above ground level. Grid spacing for the ground survey was $10 \mathrm{~m}$, $20 \mathrm{~m}$, and $25 \mathrm{~m}$ (see Figure 1). Note that the two plots are at a slightly different scale. 

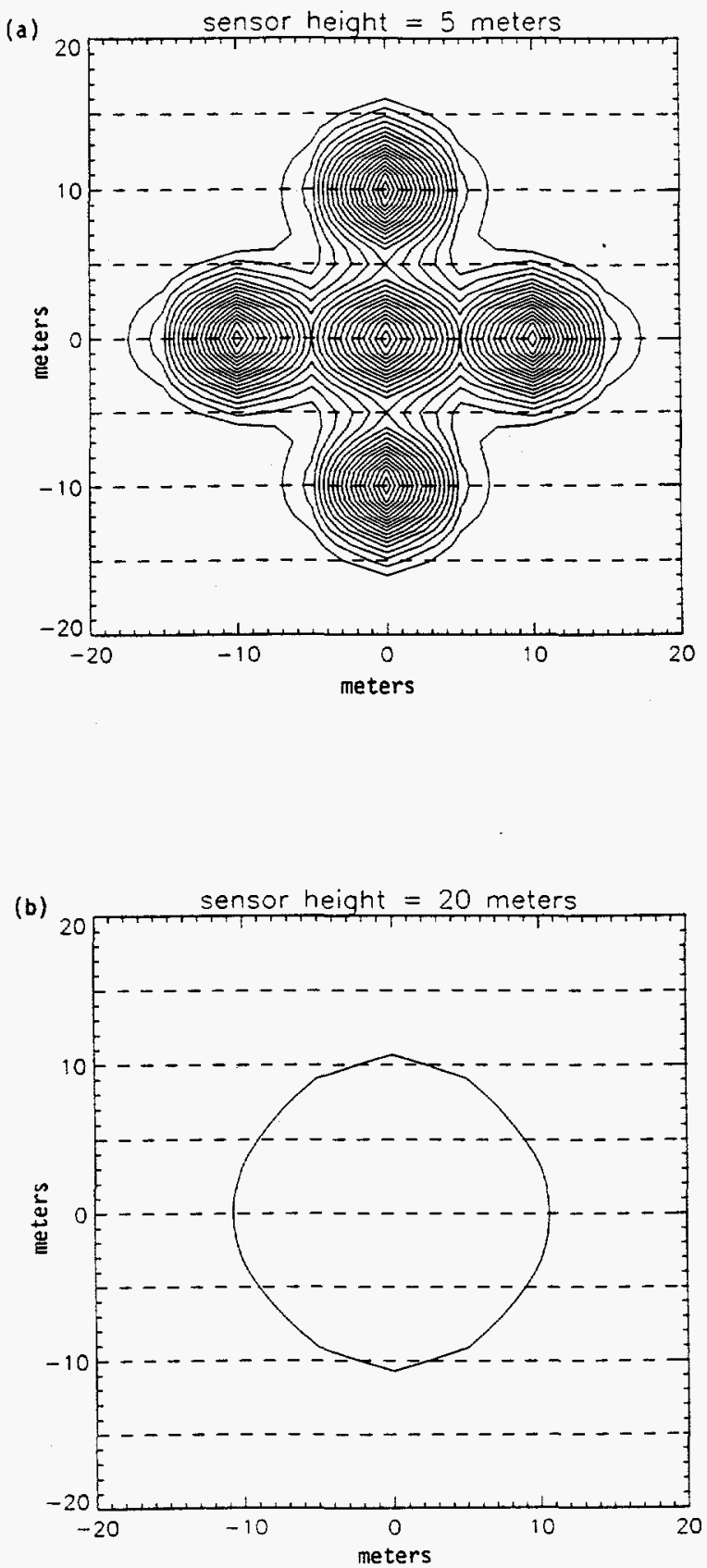

Figure 4. Total magnetic field map computed over 5 sets of drums, with each set having 20 drums. Dashed lines represent flight lines $5 \mathrm{~m}$ apart. Background is $54000 \mathrm{nT}$. Contour interval is $5 \mathrm{nT}$. (a) Total magnetic field for magnetometer at a height of $5 \mathrm{~m}$. (b) Total magnetic field for magnetometer at a height of $20 \mathrm{~m}$. 

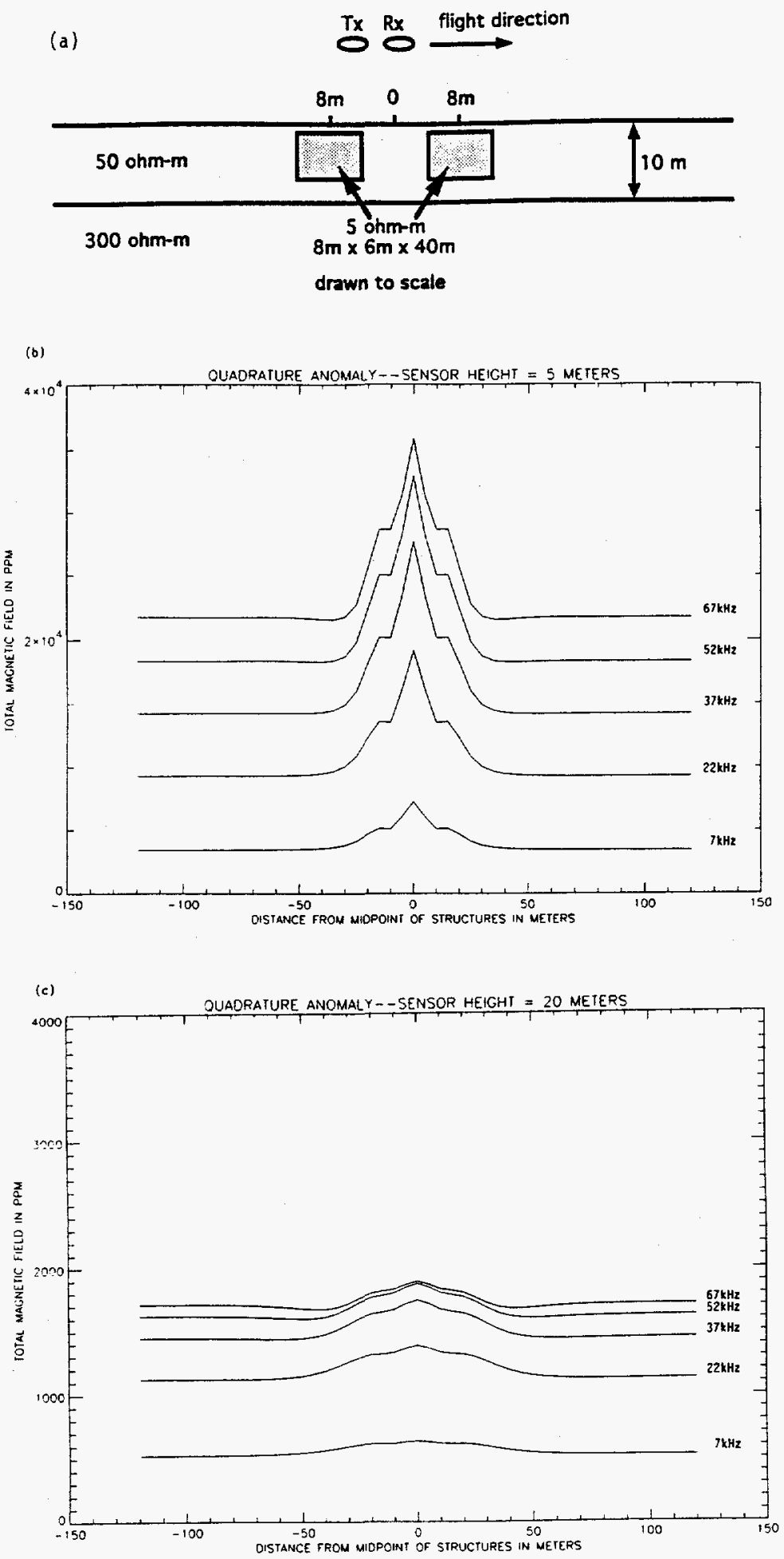

Figure 5. Quadrature component of the electromagnetic response of a multifrequency aerial electromagnetic system over two elongate conductors. The system uses horizontal coplanar coils separated by $6 \mathrm{~m}$. (a) Two conductor model. (b) Response in parts per million for a sensor height of $5 \mathrm{~m}$. (c) Response in parts per million for a sensor height of $20 \mathrm{~m}$. 